\title{
A Novel Nanocomposite of Activated Serpentine Mineral Decorated with Magnetic Nanoparticles for Rapid and Effective Adsorption of Hazardous Cationic Dyes: Kinetics and Equilibrium Studies
}

\author{
Moaaz K. Seliem 1,*, Mariusz Barczak ${ }^{2}(\mathbb{D})$, Ioannis Anastopoulos 3 (D) and \\ Dimitrios A. Giannakoudakis 4 (D) \\ 1 Faculty of Earth Science, Beni-Suef University, Beni Suef Governorate 621, Egypt \\ 2 Department of Theoretical Chemistry, Institute of Chemical Sciences, Faculty of Chemistry, Maria \\ Curie-Sklodowska University, 20-031 Lublin, Poland; mbarczak@umcs.pl \\ 3 Department of Chemistry, University of Cyprus, P.O. Box 20537, Cy-1678 Nicosia, Cyprus; \\ anastopoulos_ioannis@windowslive.com \\ 4 Institute of Physical Chemistry, Polish Academy of Sciences, Kasprzaka 44/52, 01-224 Warsaw, Poland; \\ dagchem@gmail.com \\ * Correspondence: debakyms@yahoo.com
}

Received: 16 February 2020; Accepted: 1 April 2020; Published: 5 April 2020

\begin{abstract}
A widely distributed mineral, serpentine, obtained from Wadi Ghadir (Eastern Desert in Egypt) was studied as a potential naturally and abundantly available source for the synthesis of an efficient adsorbent for aquatic remediation applications. A novel nanocomposite was synthesized after the exfoliation of the layered structure of serpentine by hydrogen peroxide treatment (serpentine (SP)), followed by decoration with magnetic $\mathrm{Fe}_{3} \mathrm{O}_{4}$ nanoparticles (MNP). The goal behind the utilization of the latter phase was to increase the environmental remediation capability and to incorporate magnetic properties at the final adsorbent, toward a better separation after the use. The fabricated composite (MNP/SP) was characterized by scanning electron microscopy (SEM), Fourier transform infrared spectroscopy (FTIR), and transmission electron microscopy (TEM). The composite's potential adsorption application toward the removal of two cationic dyes, methylene blue (MB) and malachite green (MG), was investigated. The observed adsorption kinetics was fast, and the highest uptake was observed at $\mathrm{pH}=8$, with the capacities to reach 162 and $176 \mathrm{mg} \mathrm{g}^{-1}$ for MB and MG, respectively, values significantly higher than various other materials tested against these two cationic dyes. Compared to hydrogen peroxide-treated serpentine, the removal efficiency of the composite was higher by 157 and $127 \%$ for MB and MG, respectively. The MB and MG were adsorbed because of the favorable electrostatic interactions between MNP/SP active sites and the cationic dyes. The close value capacities suggest that the difference in chemistry of the two dyes does not affect the interactions, with the later occurring via the dyes' amine functionalities. With increasing ionic strength, the adsorption of the studied basic dyes was slightly decreased, suggesting only partial antagonistic ion effect. The sorbent can be easily regenerated and reused without significant deterioration of its adsorption efficiency, which makes MNP/SP a promising adsorbent for the removal of hazardous pollutants from aquatic environments.
\end{abstract}

Keywords: serpentine; magnetic nanoparticles; adsorption; removal; cationic dyes

\section{Introduction}

Contamination of the aquatic environments due to the industrial effluents of several products, is considered to be a global challenge. Varied industries including silk, wool, leather, cotton, 
and paper discharge enormous amounts of hazardous organic water-coloring agents (dyes) in water. The continuous discharge of water-soluble organic dyes, even at low concentrations, into the aquatic system is extremely harmful and dangerous for human beings [1-3]. Acute exposure to methylene blue (MB) for instance, can cause increased heart rate, vomiting, shock, cyanosis, jaundice and quadriplegia, and irritation to the skin in humans [4]. Methylene blue (MB), one of the common basic water-soluble dyes, is used for dyeing leather, cotton, printing, calico, tannin, as well as for medicinal purposes [5]. On the other hand, contamination via malachite green (MG), a common cationic dye, was reported to cause carcinogenesis, mutagenesis, and teratogenicity [6]. Several methods with tunable operation conditions were proposed to purify water from organic dyes, including biological treatment, adsorption, coagulation, or precipitation. Among them techniques based on adsorption processes are most frequently used and preferred because of their effectiveness, low cost, and simplicity $[7,8]$. In general, adsorption of different water contaminates (heavy metals, dyes, anions, and drug residuals) using low-cost materials is a prosperous approach toward a sustainable and green-oriented future. Therefore, different clay-based adsorbents such as kaolin [9], smectite [10], raw and acid-activated bentonite [11], fibrous clay minerals [12], and red mud [13] were used to remove MB from polluted water. On the other hand, bentonite [14], halloysite nanotubes [15], natural zeolite [16], and neem sawdust [17] were used for MG uptake. Moreover, those low-cost natural materials can be further used to prepare composite sorbents with enhanced properties; one of the desired properties of the sorbent is the possibility of its easy separation using contactless magnetic forces. To achieve that the mineral phase can be used to form composite with magnetically active phase, like magnetic $\mathrm{Fe}_{3} \mathrm{O}_{4}$ nanoparticles (MNP). MNP are characterized by high surface area, biocompatibility, great number of active sites, and fast adsorbent separation from solution through magnetic field [18]. After the application of magnetic field to separate the adsorbent, varied desorbing agents can be used to remove the attached pollutants from magnetic nanoparticles and therefore MNP can be reused [19]. The synthetic MNP-coated natural and waste materials were applied significantly in the decontamination of organic pollutants $[19,20]$.

Serpentine (SP, $\left.\mathrm{Mg}_{3} \mathrm{Si}_{2} \mathrm{O}_{5}(\mathrm{OH})_{4}\right)$ is formed by the alteration of $\mathrm{Mg}$-rich silicate minerals such as pyroxene and olivine, producing the three common silicate minerals chrysotile, antigorite, and lizardite. Structurally, SP has an octahedral brucite sheet and two silica tetrahedral sheets. In addition to magnesium and silicon, aluminum, iron, and nickel can be included in the SP composition. Although serpentine is widely distributed in Egypt, eco-friendly, wide-ranging composition, and low-cost, its potential environmental applications related to the removal of hazardous species from waters and wastewaters were not considered. Recently, exfoliation of the 2:1 layered structure of $\mathrm{SP}_{\mathrm{Py}} \mathrm{H}_{2} \mathrm{O}_{2}$ resulted in facilitating the grafting of the cationic surfactant in its structure, which frequently improved the adsorption capacity of SP for Cr(VI) and fluoride [21].

The aim of this work is to synthesize a composite of $\mathrm{Fe}_{3} \mathrm{O}_{4}$ nanoparticles and $\mathrm{H}_{2} \mathrm{O}_{2}$-activated serpentine (MNP/SP) for the removal of cationic dyes (MB and MG) from contaminated aqueous solutions. The effect of different parameters on the uptake capability and the adsorption mechanism were investigated. Finally, kinetics and equilibrium studies were interpreted in the current study.

\section{Materials and Methods}

\subsection{Materials}

Herein, serpentine obtained from Wadi Ghadir, Eastern desert in Egypt was subjected to grinding and sieving to get powder with fraction size $<100$ mesh. The chemicals used were: methylene blue (MB, $\mathrm{C}_{16} \mathrm{H}_{18} \mathrm{ClN}_{3} \mathrm{~S}$, Sigma-Aldrich, CAS 122965-43-9, and purity 98.5\%), malachite green (MG, $\mathrm{C}_{23} \mathrm{H}_{25} \mathrm{~N}_{2}$, Sigma-Aldrich CAS $123333-61-9$, and purity $\left.99 \%\right)$, hydrogen peroxide $\left(30 \%, \mathrm{H}_{2} \mathrm{O}_{2}\right.$, Merck, Germany, CAS 7722-84-1), ferric chloride $\left(\mathrm{FeCl}_{3} \cdot 6 \mathrm{H}_{2} \mathrm{O}\right.$, Loba Chemie, Mumbai, India, CAS 10025-77-1, purity 97\%), iron (II) sulfate (FeSO $4.7 \mathrm{H}_{2} \mathrm{O}$, Loba Chemie, Mumbai, India, CAS 7782-63-0, purity 99\%), ammonia hydroxide solution ( $\mathrm{NH}_{4} \mathrm{OH}$, Loba Chemie, CAS 1336-21-6, purity 25\%), and distilled water. 
To obtain the required $\mathrm{pH}$ value, $\mathrm{HCl}(0.01 \mathrm{M})$ and $\mathrm{NaOH}(0.01 \mathrm{M})$ were used. The molecular structures of studied dyes (MG and $\mathrm{MB}$ ) are shown in Figure 1.

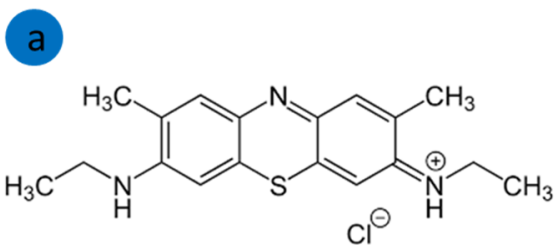

Methylene blue (MB)<smiles></smiles>

Malachite green (MG)

Figure 1. The molecular structures of the studied basic dyes.

\subsection{Preparation of the Composite Adsorbent}

Chemical activation of SP sample by $\mathrm{H}_{2} \mathrm{O}_{2}$ was carried out according to the method described previously [21]. Typically, $5 \mathrm{~g}$ of SP was added to $50 \mathrm{~mL}$ of $50 \% \mathrm{H}_{2} \mathrm{O}_{2}$ and stirred for $60 \mathrm{~min}$ at $50{ }^{\circ} \mathrm{C}$. In another glass beaker, $1.05 \mathrm{~g}$ of $\mathrm{FeSO}_{4} \cdot 7 \mathrm{H}_{2} \mathrm{O}$ and $2.1 \mathrm{~g}$ of $\mathrm{FeCl}_{3} \cdot 6 \mathrm{H}_{2} \mathrm{O}$ were dissolved in $50 \mathrm{~mL}$ of distilled water with vigorous stirring for $30 \mathrm{~min}$ at room temperature $\left(25^{\circ} \mathrm{C}\right)$. To this mixture, $15 \mathrm{~mL}$ of $\mathrm{NH}_{4} \mathrm{OH}$ as a precipitated agent $(25 \%)$ was added with continues stirring for $30 \mathrm{~min}$. The chemical precipitation technique was applied to obtain magnetic nanoparticles of $\mathrm{Fe}_{3} \mathrm{O}_{4}$ (MNP) under alkaline condition [22]. The contents of the two beakers were mixed together and stirred for $60 \mathrm{~min}$ for $50{ }^{\circ} \mathrm{C}$. The resulted magnetic product was separated by magnet before washing by distilled water and ethanol. Then, the solid phase was separated from washing solutions by centrifuge and dried at $70{ }^{\circ} \mathrm{C}$ for $24 \mathrm{~h}$. $\mathrm{MNP} / \mathrm{SP}$ was prepared according to Equation (1) [22]:

$$
\mathrm{FeSO}_{4} \cdot 7 \mathrm{H}_{2} \mathrm{O}+2 \mathrm{FeCl}_{3} \cdot 6 \mathrm{H}_{2} \mathrm{O}+8 \mathrm{NH}_{4} \mathrm{OH} \rightarrow \mathrm{Fe}_{3} \mathrm{O}_{4}+6 \mathrm{NH}_{4} \mathrm{Cl}+\left(\mathrm{NH}_{4}\right)_{2} \mathrm{SO}_{4}+17 \mathrm{H}_{2} \mathrm{O}
$$

The resulting MNP/SP composite was softly grounded and submitted for the characterization and adsorption tests.

\subsection{Characterizations}

Scanning electron microscope (SEM, JSM-6700F, JEOL, Tokyo, Japan) and transmission electron microscope (JEM-2100F, JEOL, Japan) were used to study the morphological features of the examined $\mathrm{MNP} / \mathrm{SP}$ adsorbent. Fourier transform infrared spectroscopy (FTIR) was used to identify the functional groups (active sites) of the obtained MNP/SP composite using Bruker FT/IR-2000 Spectrometer in the range of $400-4000 \mathrm{~cm}^{-1}$.

The point of zero charge $\left(\mathrm{pH}_{\mathrm{ZCP}}\right)$ of the MNP/SP was determined using previously established protocol [23,24]. Total of $0.1 \mathrm{~g}$ of MNP/SP composite was added to $50 \mathrm{~mL}$ of $0.1 \mathrm{M} \mathrm{NaCl}$ solution. The mixture was shaken at $200 \mathrm{rpm}$ for $48 \mathrm{~h}$. The difference between the initial $\mathrm{pH}$ and final $\mathrm{pH}$ (i.e., $\mathrm{pH}_{\mathrm{f}}-\mathrm{pH}_{\mathrm{i}}$ ) was plotted against $\mathrm{pH}_{\mathrm{i}}$. The point at which $\mathrm{pH}_{\mathrm{f}}-\mathrm{pH}_{\mathrm{i}}$ equals zero was the value of zero charge point $\left(\mathrm{pH}_{\mathrm{ZCP}}\right)$.

\subsection{Adsorption Experiments}

First, stock solutions (1000 $\mathrm{mg} \mathrm{L}^{-1}$ ) of MB and MG were prepared and the required concentrations were obtained by diluting the prepared stock solutions. In this study, effects of solution $\mathrm{pH}$, contact time, MB and MG initial concentrations and temperature were investigated as factors governing the adsorption process. All adsorption experiments were performed at $25{ }^{\circ} \mathrm{C}$. After separation of liquid phases in all adsorption experiment by centrifuging, a double beam UV-visible absorption 
spectrometer (Shimadzu, UV 1601) was applied to determine MB $\left(\lambda_{\max }=660 \mathrm{~nm}\right)$ and $\mathrm{MG}\left(\lambda_{\max }=\right.$ $610 \mathrm{~nm}$ ) concentrations.

In order to check the influence of $\mathrm{pH}, 100 \mathrm{mg} \mathrm{L}^{-1}$ solutions of $\mathrm{MG}$ and $\mathrm{MB}$ at different $\mathrm{pH}$ values (2.0, 3.0, 5.0, 7.0, 8.0 and 10.0) were prepared. Total of $50 \mathrm{mg}$ of the MNP/SP adsorbent was mixed with $25 \mathrm{~mL}$ of the previously prepared MG and MB solutions. The mixtures were shaken at $200 \mathrm{rpm}$ for $2 \mathrm{~h}$ using an orbital shaker (SHO-2D).

$\mathrm{MB}$ and $\mathrm{MG}$ adsorption kinetics were determined in the adsorption system containing $25 \mathrm{mg}$ of the MNP/SP and $25 \mathrm{~mL}$ solution of MB and MG $\left(100 \mathrm{mg} \mathrm{L}^{-1}\right)$. The mixtures were agitated at $200 \mathrm{rpm}$ at different contact times $(5,30,60,120,240$, and $360 \mathrm{~min})$ and $\mathrm{pH}=8.0$. The adsorbed amount $\left(q_{t}\right)$ of $\mathrm{MB}$ and $\mathrm{MG}$, were calculated from mass balance using the formula:

$$
q_{t}=\left(C_{0}-C_{t}\right) \frac{V}{m}
$$

where $C_{0}\left(\mathrm{~m} \mathrm{~L}^{-1}\right)$ is the initial concentration of $\mathrm{MB}$ (or MG), $C_{t}$ is the concentration $\left(\mathrm{mg} \mathrm{L}^{-1}\right)$ of the studied organic dyes after time $(t), \mathrm{V}$ is the volume of the solution $(\mathrm{L})$, and $\mathrm{m}$ is the mass of the adsorbent (g).

Different initial concentrations of MB and MG ranging from 50 to $200 \mathrm{mg} \mathrm{L}^{-1}$ were used in evaluation of adsorption equilibrium using $25 \mathrm{mg}$ of the MNP/SP sorbent and $25 \mathrm{~mL}$ of the prepared solution. Each adsorption system was shaken at $200 \mathrm{rpm}$ for $120 \mathrm{~min}$ at solution $\mathrm{pH}=8.0$.

The impact of increasing temperature from 30 to $60^{\circ} \mathrm{C}$ on the adsorbed amount of $\mathrm{MB}$ and MG was assessed using $25 \mathrm{mg}$ of the MNP/SP and $100 \mathrm{mg} \mathrm{L}^{-1}$ of MB and MG concentrations. The adsorption systems at the selected temperatures were shaken at $200 \mathrm{rpm}$ for $2 \mathrm{~h}$.

All MG and MB adsorption experiments were performed in triplicates and above, and the mean values of the results have been used for data evaluation, with the error to range always below $\pm 4 \%$.

\subsection{Fitting of the Adsorption Data}

To better describe the adsorption behavior of the dyes onto SP and MNP/SP and to find the possible rate-governing step, the pseudo first-order [25], the pseudo second-order [26], and intra-particle diffusion [27] equations were used in this study (Table S1). The Langmuir [28] and Freundlich [29] equilibrium adsorption models were also used to fit the adsorption data and details can be found at the Supplementary Information.

\subsection{Salinity Effect on Adsorption}

The effect of salinity on MB and MG removal was studied using $50 \mathrm{~mL}$ solution of each studied dye with a concentration of $100 \mathrm{mg} / \mathrm{L}$ and MNP/SP dose of $50 \mathrm{mg}$. Different concentrations of $\mathrm{NaCl}$, in the range from 0.2 to $1.2 \mathrm{~g} \mathrm{~L}^{-1}$ were used and all the experiments were performed more than three times.

\subsection{Reusability - Adsorption/Desorption Cycles}

$\mathrm{MB}$ and MG desorption experiment was carried out using $100 \mathrm{~mL} \mathrm{NaOH}(0.5 \mathrm{M})$ as a desorbing agent. The MNP/SP loaded with the studied dyes was continuously agitated on a rotatory shaker at $200 \mathrm{rpm}$ for $2 \mathrm{~h}$ at room temperature. The desorption process of MB and MG was repeated five times. At the end of each desorption cycle, the MNP/SP was washed three times by distilled water and dried at $70{ }^{\circ} \mathrm{C}$ for $6 \mathrm{~h}$ before the next desorption round.

\section{Results and Discussions}

\subsection{Characterization of the $\mathrm{Fe}_{3} \mathrm{O}_{4} /$ activated serpentine (MNP/SP) Adsorbent}

The as-synthesized $\mathrm{H}_{2} \mathrm{O}_{2}$-activated serpentine (SP) and $\mathrm{Fe}_{3} \mathrm{O}_{4}$ with magnetic properties (MNP) are shown in the pictures (Figure 2a,b). The structure analysis by SEM of SP revealed characteristic features as in common serpentine minerals like fibrous chrysotile and platy-like antigorite (Figure 2c). 
Activation via $\mathrm{H}_{2} \mathrm{O}_{2}$ resulted in partial separation of the layered structure of SP forming opened fractures and pits (Figure $2 \mathrm{~d}$ ). Therefore, in the case of the composite, magnetic iron oxide particles were not only deposited onto the outer SP surface, but also were impregnated in and between the resulted cracks and cavities, forming spherical nanoparticles and aggregations (Figure $2 \mathrm{~d}-\mathrm{f}$ ). The existence of these spherical nanoparticles with a high level of homogeneous dispersion, could be expected to enhance the removal of MG and MB because of the increase of the developed MNP/SP composite surface area. The TEM image of SP (Figure $2 \mathrm{~g}$ ) displays the layered structure of a smooth surface. The existence of spherical-like nanoparticles, with diameter of less than $15 \mathrm{~nm}$, anchored on the SP surface can be clearly seen in Figure $2 h$, testifying further the homogeneous dispersion.
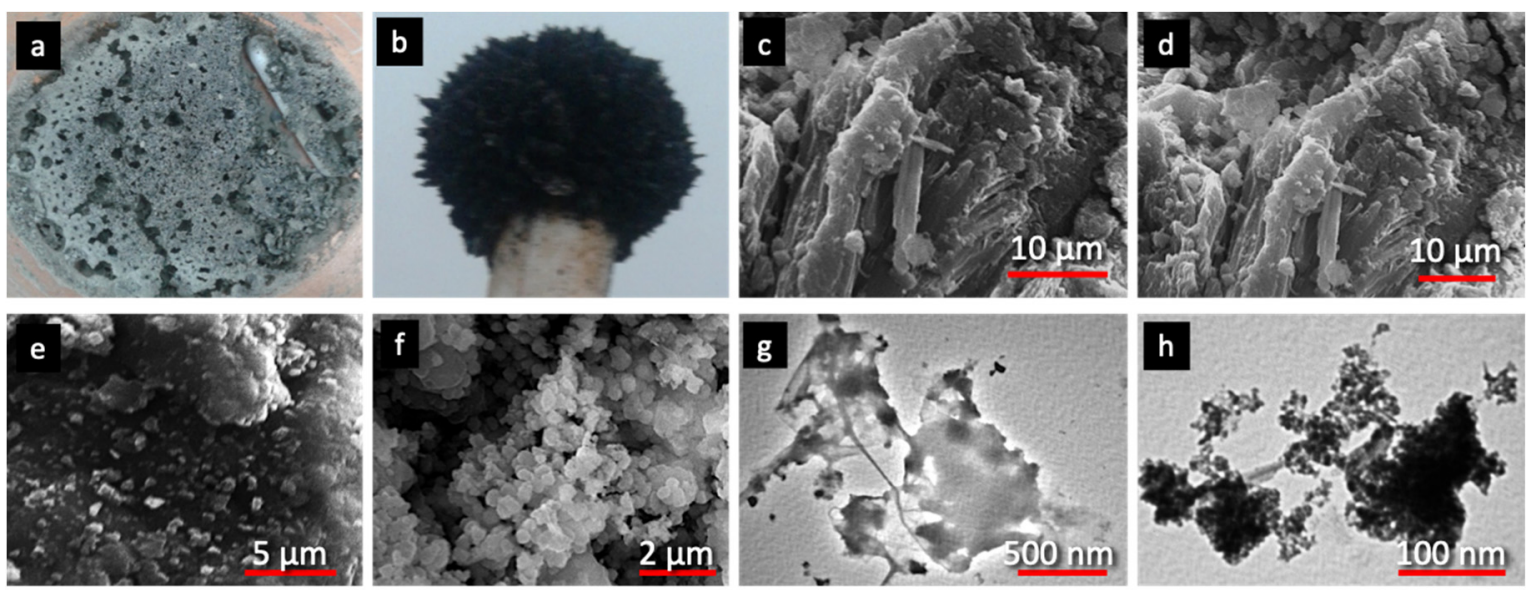

Figure 2. Photographs of serpentine (SP) (a) and magnetic $\mathrm{Fe}_{3} \mathrm{O}_{4}$ nanoparticles (MNP) (b), scanning electron microscopy (SEM) images of SP (c) and MNP/SP (d-f), transmission electron microscopy (TEM) images of SP (g) and MNP/SP (h).

The chemical composition of the as-synthesized composite was investigated by FTIR spectroscopy and the obtained spectrum is presented in Figure 3. Several absorption band can be attributed to the presence of two phase forming the final composite:

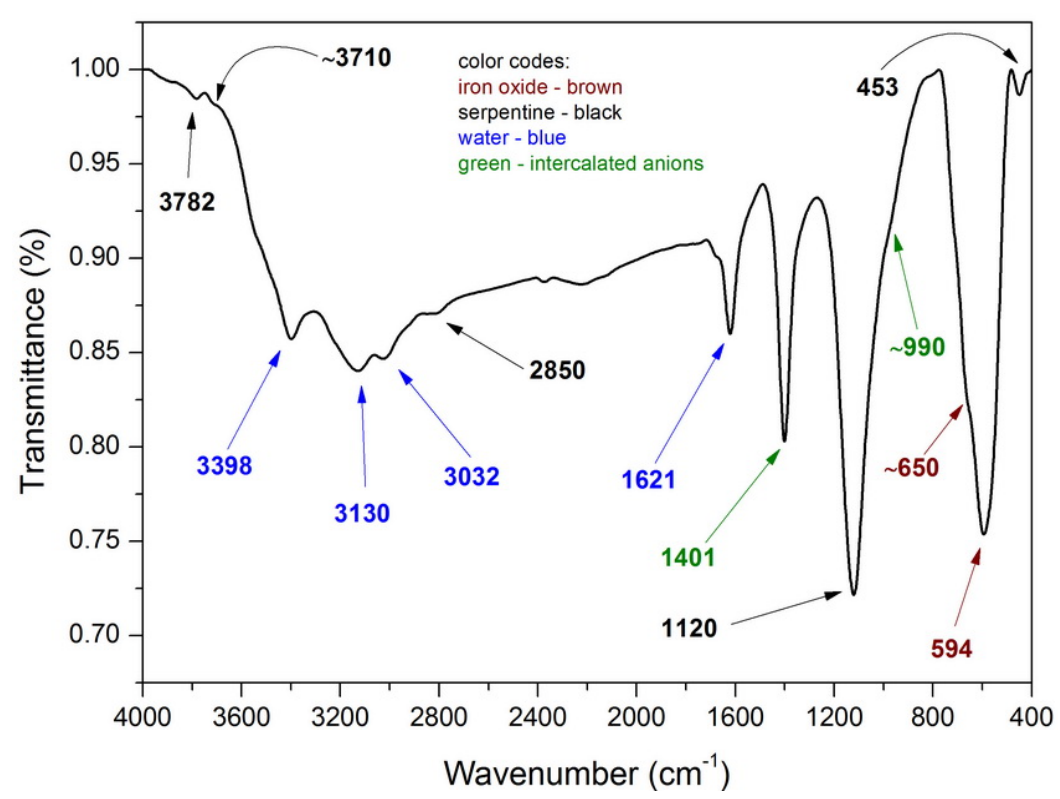

Figure 3. Fourier transform infrared spectroscopy (FTIR) spectrum of MNP/SP composite.

Since the serpentine is mainly composed of octahedral brucite sheet and two silica tetrahedral sheets, FTIR spectrum displays characteristic bands for both $\mathrm{Mg}(\mathrm{OH})_{2}$ and $\mathrm{SiO}_{2}$ phase phases. 
The absorption bands at 1120 and $453 \mathrm{~cm}^{-1}$ can be attributed to the asymmetric stretching and bending vibrations of $\mathrm{Si}-\mathrm{O}-\mathrm{Si}$ fragments in silica, respectively. The latter could also be assigned to the stretching vibrations of Mg-O (also Mg-O-Si) fragments of brucite. The band located at $3782 \mathrm{~cm}^{-1}$ is due to the presence of isolated silanol groups of silica, while the shoulder band at $\sim 3710 \mathrm{~cm}^{-1}$ is due to the stretching vibrations of $-\mathrm{OH}$ group in $\mathrm{Mg}(\mathrm{OH})_{2}$. Anions present in the interlayer region also give characteristic signals, for example carbonate at $1401 \mathrm{~cm}^{-1}$, and nitrate at $990 \mathrm{~cm}^{-1}$. The absorption bands at 1621 and $3398 \mathrm{~cm}^{-1}$ are due to the bending and stretching vibrations of hydroxy groups of physically absorbed water. Because of high surface heterogeneity, the water is bound to different chemical groups present on the surface, thus apart from the absorption band at $3398 \mathrm{~cm}^{-1}$ two other absorption bands corresponding to the stretching vibrations of water are also observed at 3130 and $3032 \mathrm{~cm}^{-1}$ [30-32]. $\mathrm{Fe}_{3} \mathrm{O}_{4}$ particles and serpentine. The presence of absorption band located at $594 \mathrm{~cm}^{-1}$ and its shoulder at $\sim 650 \mathrm{~cm}^{-1}$ can be attributed to the bending vibrations associated with the presence of Fe-O (including Fe-O-Si) bonds [33].

\subsection{Effect of $p H$ on Methylene Blue and Malachite Green Adsorption}

The effect of $\mathrm{pH}$ on dyes uptake using MNP/SP is shown in Figure 4. Over the selected $\mathrm{pH}$ range, the uptake of $\mathrm{MB}$ and $\mathrm{MG}$ was improved by increasing the $\mathrm{pH}$, showing the maximum removal efficiencies (above 95\%) at $\mathrm{pH} \geq 8$. This behavior can be explained by the presence of different functional groups at MNP/SP interface that can be differently charged with changing $\mathrm{pH}$ values. At $\mathrm{pH}$ 2-3, the MNP/SP active sites surface become more positive (i.e., protonated functional groups as $-\mathrm{OH}_{2}{ }^{+}$, $\mathrm{Si}-\mathrm{OH}^{+}$) because of the high concentration of the competitive $\mathrm{H}^{+}$in solutions [34-36]. Thus, the strong electrostatic repulsion between the positively charged MNP/SP active sites and the cationic dyes results in decreasing the MB and MG uptakes. At the solution $\mathrm{pH} 4-6$, the uptake of the dyes is significantly increased. At $\mathrm{pH}>7$, strong electrostatic attraction between deprotonated groups and the studied dyes improved the adsorption processes greatly. Moreover, the point of zero-charge $\left(\mathrm{pH}_{\mathrm{ZCP}}\right)$ was found to be equal to 6.3, indicating that the MNP/SP active sites will bind the dyes more efficiently above this value of $\mathrm{pH}$, because of the favorable electrostatic interactions, which govern the MB and MG adsorption as shown below:

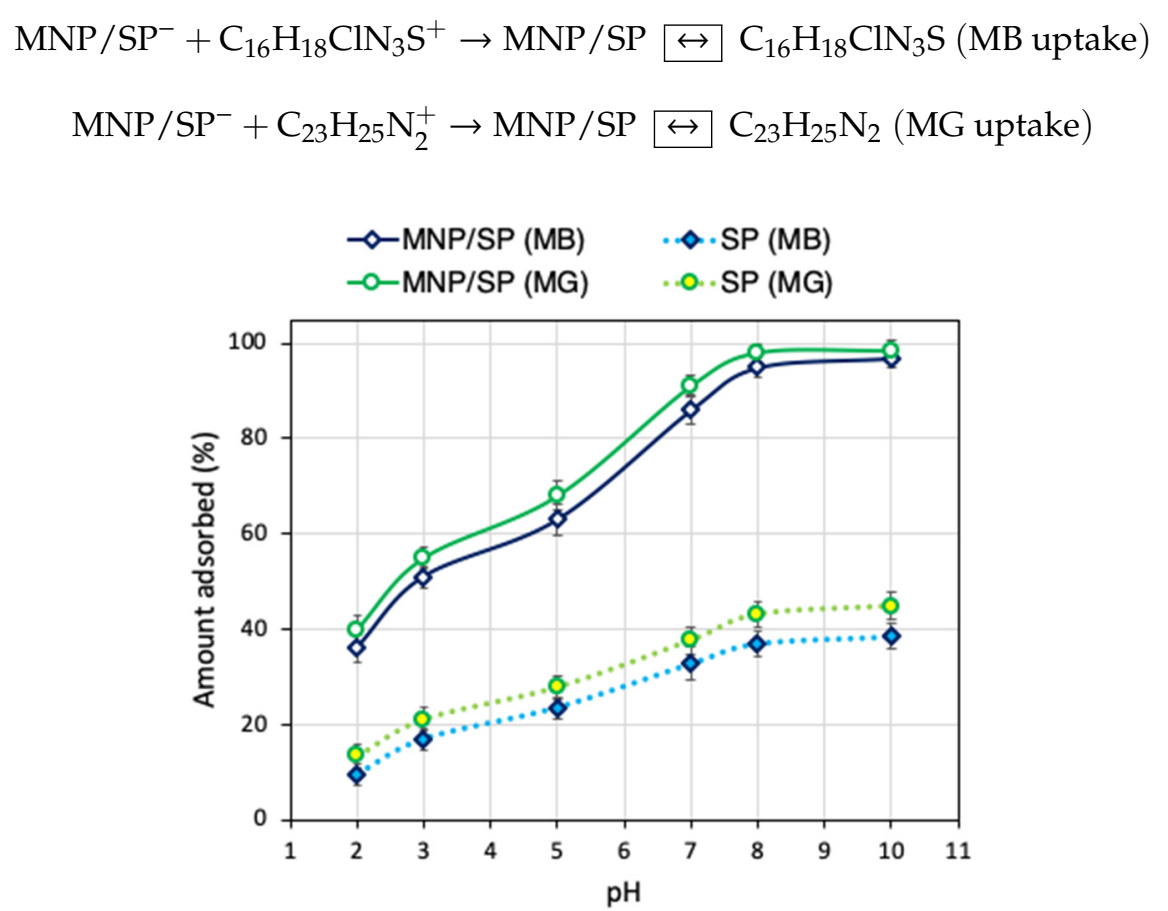

Figure 4. Effect of $\mathrm{pH}$ on adsorption of methylene blue (MB) and malachite green (MG) by $\mathrm{H}_{2} \mathrm{O}_{2}$-activated serpentine (SP) and iron oxide modified SP (MNP/SP). 
For these reasons, the adsorption experiments in this work were run in $\mathrm{pH}=8$. Removal tests were performed also with pure modified serpentine (SP) at different $\mathrm{pH}$ and the results are collected in Figure 4 in comparison with the values for MNP/SP. Under the entire $\mathrm{pH}$ range, the removal capability for the composite material was more than 2.2-folds higher. At $\mathrm{pH}=8$, the $\mathrm{MB}$ removal was $157 \%$ higher for MNP/SP compared to the SP, while for MG 127\% higher.

\subsection{Effect of Contact Time on $M B$ and $M G$ Adsorption}

The adsorbed amounts of both dyes as a function of contact time are presented in Figure 5a. Three steps of MB and MG uptake (i.e., steps 1, 2, and 3 representing $\mathrm{t}<60 \mathrm{~min}, 60<\mathrm{t}<120$ min and $120<\mathrm{t}<360 \mathrm{~min}$, respectively) can be seen, looking at the kinetic data. The first step is very rapid because of the accessibility of great number of MNP/SP active sites for MB and MG adsorption [37]. Step 2 is attributed to the intra-particle diffusion mass transfer reflecting little dyes uptake in this period. In the final step of MB and MG adsorption, the removed amounts of the studied organic dyes were nearly constant in the time range of 120-360 min because of the saturation of MNP/SP active sites by dyes molecules [37].
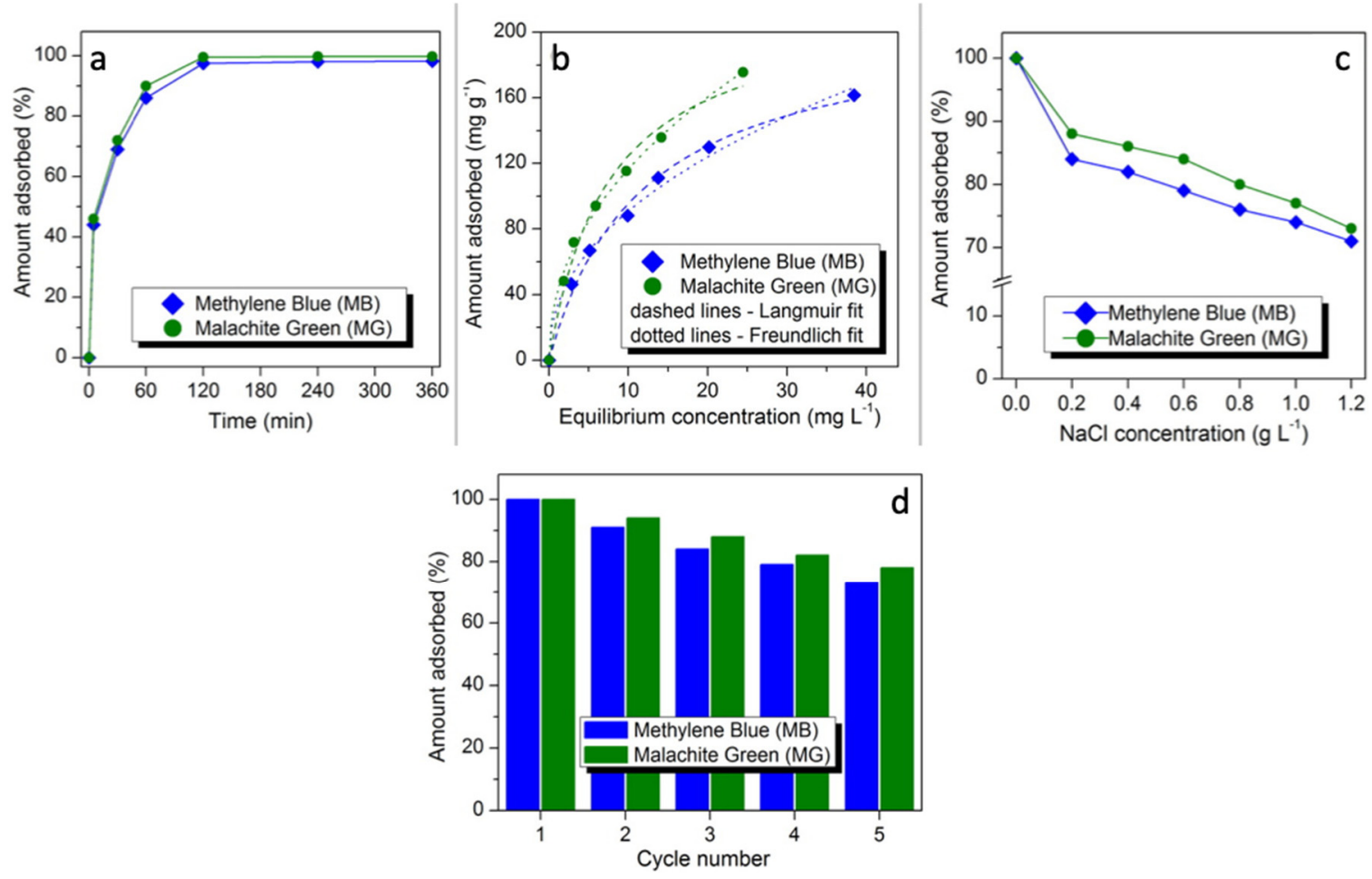

Figure 5. Effect of contact time on adsorption of dyes (a), adsorption isotherms with their fitting to Langmuir and Freundlich models (b), effect of $\mathrm{NaCl}$ addition on adsorption of dyes (c), relative adsorption uptakes after sorbent regeneration (d). Please note that fitting data are given in the Supplementary material.

\subsection{Adsorption Kinetics and Diffusion Mechanism}

The parameters of the pseudo first-order and the pseudo second-order equations were determined from the linear and non-linear plots (Figures S1 and S2) and the obtained results are given in Table 1. Based on the $R^{2}$ values, the pseudo second-order equation $\left(R^{2}>0.99\right)$ fitted well with the MB and MG adsorption processes as compared to the pseudo first-order $\left(R^{2}<0.95\right)$. Moreover, the calculated $q_{e}$ obtained from the pseudo-second order fitting is very close with the experimental $q_{e}$ values confirming the validity of this model in fitting the MG and MB data. The fitting with the intra-particle diffusion model is shown in Figures S2 and S3. During all periods of interaction times, the plot was divided into three lines. The first sharp line could be linked to the external mass transfer of MG and MB from 
the contaminated solution to the external active sites of the MNP/SP composite [38]. The lines 2 and 3 reflected the control of pore-diffusion and saturation stages, respectively [30]. The non-linear plots of the pseudo first-order and the pseudo second-order kinetic models of MB and MG are presented in Figure S3 and the obtained parameters are listed in Table S2.

Table 1. Comparison of adsorption capacities (based on Langmuir model) for different materials reported in the literature and the obtained MNP/SP material.

\begin{tabular}{cccc}
\hline Adsorbate & Adsorbent & Sorption Capacity $\mathbf{~ m g ~}^{-\mathbf{1})}$ & Reference \\
\hline MB & Montmorillonite & 64 & {$[20]$} \\
MB & $\mathrm{Fe}_{3} \mathrm{O}_{4} /$ montmorillonite & 106 & {$[20]$} \\
MB & Fibrous clay minerals & $39-85$ & {$[12]$} \\
MB & Mn-doped mesoporous MCM-41 silica & 132 & {$[39]$} \\
MB & Purified diatomite & 105 & {$[34]$} \\
MB & $\mathrm{Chitosan}_{\text {magnetic silica }}$ & 201 & {$[40]$} \\
MB & $\mathrm{Fe}_{3} \mathrm{O}_{4} /$ serpentine composite & 201 & Current study \\
\hline MG & Bentonite & 179 & {$[14]$} \\
MG & Activated carbon & 57 & {$[41]$} \\
MG & Natural zeolite & 24 & {$[16]$} \\
MG & Biocarbon prepared from plant root & 8 & {$[42]$} \\
MG & Halloysite nanotubes & 100 & {$[15]$} \\
MG & Modified rice husk & 12 & {$[43]$} \\
MG & Degreased coffee bean & 55 & {$[44]$} \\
MG & $\mathrm{Fe}_{3} \mathrm{O}_{4} /$ serpentine composite & 218 & Current study \\
\hline
\end{tabular}

\subsection{Adsorption Isotherms}

Based on Langmuir assumption, MB and MG adsorption occurs at similar active sites of the prepared MNB/SP composite. The $q_{\max }$ and $b$ parameters of Langmuir model were calculated from the relation between of $C_{e} / q_{\mathrm{e}}$ and $C_{\mathrm{e}}$ (Figure S4) and the results are given in Table S3. The dimensionless separation factor $\left(R_{S}\right)$ of the Langmuir isotherm model was determined from the following equation [38].

$$
R_{s}=\frac{1}{1+k_{L} C_{0}}
$$

The calculated $R_{s}$ values are in the range $0.05-0.09$ for $\mathrm{MB}$ and $\mathrm{MG}$ indicating favorable adsorption processes of both dyes.

According to Freundlich equation, uptake of MB and MG takes place at heterogeneous active sites forming more than one layer (multilayer) onto the MNP/SP surface. Indeed, apart from monolayer formation governed by electrostatic interactions, some part of the dyes can be adsorbed by $\pi-\pi$ interactions between the dyes molecules [36]. The parameters of Freundlich model ( $\mathrm{K}_{\mathrm{F}}$ and $\left.n\right)$ were determined (cf. Table S3) from the linear relation between $\log q_{e}$ versus $\log C_{e}$ (Figure S4). The relation between $C_{e}$ and $q_{e}$ was used in fitting the MB and MG experimental data to the non-linear forms of Langmuir and Freundlich models and the obtained parameters are given in Table S2. Based on $\mathrm{R}^{2}$ values determined for the two models (cf. Table S3), it can be concluded that adsorption of MB and MG dyes can be fitted using both of them.

The most important outcome that can be derived from all the above presented and discussed results is that the removal efficiency of the composite is almost equal for both dyes. Considering the molecular weight of MB (319.9 $\left.\mathrm{mol} \mathrm{g}^{-1}\right)$ and MG (364.9 $\left.\mathrm{mol} \mathrm{g}^{-1}\right)$, we can suggest that specific sites are responsible for the adsorption. Comparing the molecular structures (cf. Figure 1), it can be also suggested that the size and chemical differences does not affect the interactions involved in adsorption, since adsorption is driven by the interactions of the terminal amine groups located on the edges of the dyes molecules, thus equally accessible for both dyes regardless of their molecular sizes. 


\subsection{Comparison of the MNP/SP Adsorbent with Other Studies}

Table 1 collects the values of maximum adsorption capacities of MB and MG by the as-synthesized $\mathrm{MNP} / \mathrm{SP}$ of this study as compared to natural and modified materials. Based on the $q_{\max }$ values of $\mathrm{MB}$ (201 $\left.\mathrm{mg} \mathrm{g}^{-1}\right)$ and MG (218 $\left.\mathrm{mg} \mathrm{g}^{-1}\right)$, the MNP/SP sorbent is measured as a promising composite for the removal of the selected cationic organic dyes (MB and $\mathrm{MG}$ ) from the contaminated solutions.

\subsection{Temperature Effect on $M B$ and $M G$ Adsorption}

At $25^{\circ} \mathrm{C}$, the removed amounts of $\mathrm{MB}$ and MG are 84 and $88 \mathrm{mg} \mathrm{g}^{-1}$, respectively. With increasing the solution temperature to $60{ }^{\circ} \mathrm{C}$, the adsorbed amounts decreased to 70 and $73 \mathrm{mg} \mathrm{g}^{-1}$ for MB and MG, respectively. The observed decrease testifies to the exothermic nature of adsorption processes occurring during uptakes of the dyes [45].

\subsection{Effect of Salinity on $M B$ and $M G$ Adsorption}

Dyeing method is associated with increasing salt concentration and therefore, the ionic strength effect on the MG and MB adsorption onto the MNP/SP was investigated. It was observed that with an increase in the salt concentration from 0.2 to $1.2 \mathrm{~g} \mathrm{~L}^{-1}$, the removed amounts were decreased from 88 to $73 \mathrm{mg} \mathrm{g}^{-1}$ in case of MG and from 84 to $71 \mathrm{mg} \mathrm{g}^{-1}$ in case of MB (Figure $5 \mathrm{c}$ ). This may be due to the screening effect of salt ions, which resulted in suppressing the electrostatic attractions between MNP/SP adsorbent and the dyes molecules [46]. Furthermore, this decrease in the uptake values can be related to the occupation of some MNP/SP active sites by sodium ions.

\subsection{The Reusability Studies}

Possibility of the multiple use of any sorbent is one of the most important issues determining the possibility of its real use in adsorption-based industrial processes [47-52]. Herein, five adsorption/ desorption cycles were run to evaluate the possibility of regeneration and reusing of the synthesized composite sorbent. The results are presented in Figure $5 \mathrm{~d}$. As it can be seen the regenerated sorbent maintained high sorption retention effectiveness after five cycles toward both dyes. The adsorption capacity of the sorbent after four adsorption/desorption cycles is $73 \%$ and $78 \%$ for $\mathrm{MB}$ and $\mathrm{MG}$, respectively. The decrease of sorption capacities for all the samples can be linked with two possible factors: (i) Irreversible adsorption of some amount of the dyes that could not be desorbed using $0.5 \mathrm{NaOH}$ and (ii) gradual elimination of porosity and surface chemistry upon processing (including water-driven processes occurring during sorption cycles and $\mathrm{NaOH}$-driven during desorption cycles). Nevertheless, the observed retention of adsorption effectiveness toward MB and MG after five cycles clearly showed the applicability of the obtained sorbent.

\section{Conclusions}

A new composite of activated serpentine and magnetic iron oxide nanoparticles was successfully fabricated, characterized, and tested as adsorbent of two cationic dyes (methylene blue and malachite green). The sorbent exhibited the maximum adsorption uptake at $\mathrm{pH}=8$. Kinetic data revealed that the equilibrium was reached after $120 \mathrm{~min}$ of shaking time and the adsorption rate followed the pseudo second-order kinetic model. The obtained sorbent could adsorb as much as $162 \mathrm{mg} \mathrm{g}^{-1} \mathrm{of} \mathrm{MB}^{-1}$ and $176 \mathrm{mg} \mathrm{g}^{-1}$ of MG. The sorbent could be easily regenerated using diluted $\mathrm{NaOH}$ solution and reused many times while maintaining over $70 \%$ effectiveness after five adsorption cycles. This study clearly shows that serpentine-derived composite materials can be successfully used for fast, efficient, and cost-effective adsorptive removal of hazardous dyes from waters and wastewaters. Moreover, the interactions with the adsorbent surface occur via the cationic amine functionalities, since the adsorption-desorption capability was found similar for both MB and MG.

Supplementary Materials: The following are available online at http://www.mdpi.com/2079-4991/10/4/684/s1, Figure S1: Effect of contact time (a), fitting the kinetic data with pseudo-first-order (b), pseudo-second-order (c), 
and intra-particle diffusion model (d) on MB uptake; Figure S2: Effect of contact time (a), fitting of the kinetic data with pseudo-first order (b), pseudo-second order (c), and intra-particle diffusion model (d) on MG uptake; Figure S3: The non-linear plots of the pseudo-first order and the pseudo-second order kinetic models of MB and MG adsorption onto MNP/SP composite; Figure S4: Linear Langmuir fitting (a,b), linear Freundlich fitting $(\mathrm{c}, \mathrm{d})$, and the non-linear fitting using Langmuir and Freundlich models (e,f)., Table S1: Kinetics models for dye adsorption by MNP/SP composite; Table S2: Fitting the kinetic data with different kinetic models; Table S3: Parameters of isotherms models for MB and MG uptake by MNP/SP adsorbent.

Author Contributions: M.K.S.: methodology, writing—original draft; M.B.: writing—review and editing; I.A.: review and editing; D.A.G.: writing-review and editing. All authors have read and agreed to the published version of the manuscript.

Funding: This research was funded by STDF, Grant number 25552.

Acknowledgments: M.K.S. thanks the Mineral Technology and Environmental Application Lab (META), Faculty of Earth Science for providing the raw serpentine used in this study.

Conflicts of Interest: The authors declare no conflict of interest.

\section{References}

1. Li, Z.; Wang, G.; Zhai, K.; He, C.; Li, Q.; Guo, P. Methylene blue adsorption from aqueous solution by loofah sponge-based porous carbons. Colloids Surf. A 2018, 538, 28-35. [CrossRef]

2. Mobarak, M.; Selim, A.Q.; Mohamed, E.A.; Seliem, M.K. Experimental results and theoretical statistical modeling of malachite green adsorption onto MCM-41silica/rice husk composite modified by beta radiation. J. Mol. Liq. 2019, 273, 68-82. [CrossRef]

3. Saffari, R.; Shariatinia, Z.; Jourshabani, M. Synthesis and photocatalytic degradation activities of phosphorus containing $\mathrm{ZnO}$ microparticles under visible light irradiation for water treatment applications. Environ. Pollut. 2020, 259, 1-15. [CrossRef] [PubMed]

4. Xiao, X.; Zhang, F.; Feng, Z.; Deng, S.; Wang, Y. Adsorptive removal and kinetics of methylene blue from aqueous solution using NiO/MCM-41composite. Phys. E 2015, 65, 4-12. [CrossRef]

5. VGupta, K.; Ali, S.I.; Saini, V.K. Removal of Rhodamine B, Fast Green, and Methylene Blue from Waste water Using Red Mud, an Aluminum Industry Waste. Ind. Eng. Chem. Res. 2004, 43, 1740-1747.

6. Ahmad, M.A.; Alrozi, R. Removal of malachite green dye from aqueous solution using rambutan peel-based activated carbon: Equilibrium, kinetic and thermodynamic studies. Chem. Eng. J. 2011, 171, 510-516. [CrossRef]

7. Agarwal, S.; Tyagi, I.; Gupta, V.K.; Mashhadi, S.; Ghasemi, M. Kinetics and thermodynamics of malachite green dye removal from aqueous phase using iron nanoparticles loaded on ash. J. Mol. Liq. 2016, 223, 1340-1347. [CrossRef]

8. Seliem, M.K.; Mohamed, E.A.; Selim, A.Q.; Shahien, M.G.; Abukhadra, M.R. Synthesis of Na-A zeolites from natural and thermally activated Egyptian kaolinite: Characterization and competitive adsorption of copper ions from aqueous solutions. Int. J. Bioassays 2015, 4, 4423-4430.

9. Tehrani, A.R.; Nikkar, H.; Mahmoodi, N.M.; Makazi, M.; Menger, F.M. The sorption of cationic dyes onto kaolin: Kinetic, isotherm and thermodynamic studies. Desalination 2011, 266, 274-280. [CrossRef]

10. Hajjaji, M.; Alami, A. Influence of operating conditions on methylene blue uptake by a smectite rich clay fraction. Appl. Clay Sci. 2009, 44, 127-129. [CrossRef]

11. Hajjaji, M.; el Arfaoui, H. Adsorption of methylene blue and zinc ions on raw and acid-activated bentonite from Morocco. Appl. Clay Sci. 2009, 46, 418-421. [CrossRef]

12. Hajjaji, M.; Alami, A.; el Bouadili, A. Removal of methylene blue from aqueous solution by fibrous clay minerals. J. Hazard. Mater. 2006, 135, 188-192. [CrossRef] [PubMed]

13. Wang, S.; Boyjoo, Y.; Choueib, A.; Zhu, Z.H. Removal of dyes from aqueous solution using fly ash and red mud. Water Res. 2005, 39, 129-138. [CrossRef] [PubMed]

14. Bulut, E.; Ozacar, M.; Sengil, I.A. Adsorption of malachite green onto bentonite: Equilibrium and kinetic studies and process design. Microporous Mesoporous Mater. 2008, 115, 234-246. [CrossRef]

15. Kiani, G.; Dostali, M.; Rostami, A.; Khataee, A.R. Adsorption studies on the removal of malachite green from aqueous solutions onto halloysite nanotubes. Appl. Clay Sci. 2011, 54, 34-39. [CrossRef]

16. Han, R.; Wang, Y.; Sun, Q.; Wang, L.; Song, J.; He, X.; Dou, C. Malachite green adsorption onto natural zeolite and reuse by microwave irradiation. J. Hazard. Mater. 2010, 175, 1056-1061. [CrossRef] 
17. Khattria, S.D.; Singh, M.K. Removal of malachite green from dye wastewater using neem sawdust by adsorption. J. Hazard. Mater. 2009, 167, 1089-1094. [CrossRef]

18. Keyhanian, F.; Shariati, S.; Faraji, M.; Hesabi, M. Magnetite nanoparticles with surface modification for removal of methyl violet from aqueous solutions. Arab. J. Chem. 2016, 9, S348-S354. [CrossRef]

19. Pirbazari, A.E.; Saberikhaha, E.; Kozani, S.S.H. Fe3O4-wheat straw: Preparation, characterization and its application for methylene blue adsorption. Water Resour. Ind. 2014, 7-8, 23-37. [CrossRef]

20. Chang, J.; Ma, J.; Ma, Q.; Zhang, D.; Qiaoa, N.; Hu, M.; Ma, H. Adsorption of methylene blue onto $\mathrm{Fe}_{3} \mathrm{O}_{4}$ /activated montmorillonite nanocomposite. Appl. Clay Sci. 2016, 119, 132-140. [CrossRef]

21. Mobarak, M.; Mohamed, E.A.; Selim, A.Q.; Sellaoui, L.; Laminec, A.B.; Erto, A.; Bonilla-Petriciolete, A.; Seliem, M.K. Surfactant-modified serpentine for fluoride and $\mathrm{Cr}(\mathrm{VI})$ adsorption in single and binary systems: Experimental studies and theoretical modeling. Chem. Eng. J. 2019, 360, 333-343. [CrossRef]

22. Panneerselvam, P.; Morad, N.; Tan, K.A. Magnetic nanoparticle $\left(\mathrm{Fe}_{3} \mathrm{O}_{4}\right)$ impregnated onto tea waste for the removal of nickel (II) from aqueous solution. J. Hazard. Mater. 2011, 186, 160-168. [CrossRef] [PubMed]

23. Selim, A.Q.; Mohamed, E.A.; Mobarak, M.; Zayed, A.M.; Seliem, M.K.; Komarneni, S. Cr(VI) uptake by a composite of processed diatomite with MCM-41: Isotherm, kinetic and thermodynamic studies. Microporous Mesoporous Mater. 2018, 260, 84-92. [CrossRef]

24. Barakat, M.A.; Kumar, R.; Balkhyour, M.; Taleb, M.A. Novel $\mathrm{AlO}_{3} / \mathrm{GO} /$ halloysite nanotube composite for sequestration of anionic and cationic dyes. Rsc Adv. 2019, 9, 13916-13926. [CrossRef]

25. Langergren, S.; Svenska, B.K. Veternskapsakad, Zur theorie der sogenannten adsorption geloester stoffe. Handlingar 1898, 24, 1-39.

26. YHo, S.; McKay, G. Pseudo-second order model for sorption processes. Process Biochem. 1999, 34, 451-465.

27. Weber, J.C.; Morris, W.J. Proceedings of International Conference on Water Pollution Symposium; Pergamon Press: Oxford, UK, 1962.

28. Langmuir, I. The constitution and fundamental properties of solids and liquids. J. Am. Chem. Soc. 1916, 38, 2221-2295. [CrossRef]

29. Freundlich, H.M.F. Over the adsorption in solution. J. Phys. Chem. 1906, 57, 385-471.

30. Mobarak, M.; Selim, A.Q.; Mohamed, E.; Seliem, M.K. Modification of organic matter-rich clay by a solution of cationic surfactant/H2O2: A new product for fluoride adsorption from solutions. J. Clean. Prod. 2018, 192, 712-721. [CrossRef]

31. Tan, T.C.N.; Sen, T.K. Aqueous-phase methylene blue (MB) dye removal by mixture of eucalyptus bark (EB) biomass and kaolin clay (KC) adsorbents: Kinetics, thermodynamics, and isotherm modeling. Sep. Sci. Technol. 2019, 55, 1036-1050. [CrossRef]

32. Selim, A.Q.; Sellaoui, L.; Mobarak, M. Statistical physics modeling of phosphate adsorption onto chemically modified carbonaceous clay. J. Mol. Liq. 2019, 279, 94-107. [CrossRef]

33. Wang, G.; Hua, Y.; Su, X.; Komarneni, S.; Ma, S.; Wang, Y. Cr(VI) adsorption by montmorillonite nanocomposites. Appl. Clay Sci. 2016, 124-125, 111-118. [CrossRef]

34. Mohamed, E.A.; Selim, A.Q.; Zayed, A.M.; Komarneni, S.; Mobarak, M.; Seliem, M.K. Enhancing adsorption capacity of Egyptian diatomaceous earth by thermo-chemical purification: Methylene blue uptake. J. Colloid Interface Sci. 2019, 534, 408-419. [CrossRef] [PubMed]

35. Hameed, B.H.; El-Khaiary, M.I. Malachite green adsorption by rattan sawdust: Isotherm, kinetic and mechanism modeling. J. Hazard. Mater. 2008, 159, 574-579. [CrossRef]

36. Seliem, M.K.; Komarneni, S. Equilibrium and kinetic studies for adsorption of iron from aqueous solution by synthetic Na-A zeolites: Statistical modeling and optimization. Micropor. Mesopor. Mater. 2016, 228, $266-274$. [CrossRef]

37. Seliem, M.K.; Komarneni, V.; Byrne, T.; Cannon, F.S.; Shahien, M.G.; Khalil, A.A.; El-Gaid, I.M.A. Removal of Perchlorate by synthetic organosilica and organoclays: Kinetic and Isotherm Studies. Appl. Clay Sci. 2013, 71, 21-26. [CrossRef]

38. Seliem, M.K.; Komarneni, S.; Khadra, M.R.A. Phosphate removal from solution by composite of MCM-41 silica with rice husk: Kinetic and equilibrium studies. Microporous Mesoporous. Mater. 2016, 224, 51-57. [CrossRef]

39. Shao, Y.; Wang, X.; Kang, Y.; Shu, Y.; Sun, Q.; Li, L. Application of Mn/MCM-41 as an adsorbent to remove methyl blue from aqueous solution. J. Colloid Interface Sci. 2014, 429, 25-33. [CrossRef] 
40. Li, Y.; Zhou, Y.; Nie, W.; Song, L.; Chen, P. Highly efficient methylene blue dyes removal from aqueous systems by chitosan coated magnetic mesoporous silica nanoparticles. J. Porous Mater. 2015, 22, 1383-1392. [CrossRef]

41. Rahman, I.A.; Saad, B.; Shaidan, S.; Rizal, E.S.S. Adsorption characteristics of malachite green on activated carbon derived from rice husks produced by chemical-thermal process. Bioresour. Technol. 2005, 96, 1578-1583. [CrossRef]

42. Zhang, J.; Li, Y.; Zhang, C.; Jing, Y. Adsorption of malachite green from aqueous solution onto carbon prepared from Arundo donax root. J. Hazard. Mater. 2008, 150, 774-782. [CrossRef] [PubMed]

43. Chowdhury, S.; Mishra, R.; Saha, P.; Kushwaha, P. Adsorption thermodynamics, kinetics and isosteric heat of adsorption of malachite green onto chemically modified rice husk. Desalination 2011, 265, 159-168. [CrossRef]

44. Baek, M.; Ijagbemi, C.O.; Jin, S.; Kim, D. Removal of malachite green from aqueous solution using degreased coffee bean. J. Hazard. Mater. 2010, 176, 820-828. [CrossRef] [PubMed]

45. Albadarin, A.B.; Mangwandi, C.; Muhtaseb, A.A.; Walker, G.; Allen, S.; Ahmad, M.N.M. Kinetic and thermodynamics of chromium ions adsorption onto low-cost dolomite adsorbent. Chem. Eng. J. 2012, 179, 193-202. [CrossRef]

46. Hu, Y.; Guo, T.; Ye, X.; Li, Q.; Guo, M.; Liu, H.; Wu, Z. Dye adsorption by resins: Effect of ionic strength on hydrophobic and electrostatic interactions. Chem. Eng. J. 2013, 228, 392-397. [CrossRef]

47. Barczak, M.; Dobrowolski, R.; Borowski, P.; Giannakoudakis, D.A. Pyridine-, thiol- and amine-functionalized mesoporous silicas for adsorptive removal of pharmaceuticals. Microporous Mesoporous Mater. 2020, 299, 1-8. [CrossRef]

48. Barczak, M. Amine-modified mesoporous silicas: Morphology-controlled synthesis toward efficient removal of pharmaceuticals. Microporous Mesoporous Mater. 2019, 278, 354-365. [CrossRef]

49. Geczo, A.; Giannakoudakis, D.A.; Triantafyllidis, K.; Elshaer, M.R.; Rodríguez-Aguado, E.; Bashkova, S. Mechanistic insights into acetaminophen removal on cashew nut shell biomass-derived activated carbons. Environ. Sci. Pollut. Res. 2020. [CrossRef]

50. Saroyan, H.S.; Bele, S.; Giannakoudakis, D.A.; Samanidou, V.F.; Bandosz, T.J.; Deliyanni, E.A. Degradation of endocrine disruptor, bisphenol-A, on mixed oxidation state manganese oxide/modified graphite oxide composite: A role of carbonaceous phase. J. Colloid Interface Sci. 2019, 539, 516-524. [CrossRef]

51. Giannakoudakis, D.A.; Hosseini-Bandegharaei, A.; Tsafrakidou, P.; Triantafyllidis, K.S.; Kornaros, M.; Anastopoulos, I. Aloe vera waste biomass-based adsorbents for the removal of aquatic pollutants: A review. J. Environ. Manag. 2018, 227, 354-364. [CrossRef]

52. Anastopoulos, I.; Pashalidis, I.; Hosseini-Bandegharaei, A.; Giannakoudakis, D.A.; Robalds, A.; Usman, M.; Escudero, L.B.; Zhou, Y.; Colmenares, J.C.; Núñez-Delgado, A.; et al. Agricultural biomass/waste as adsorbents for toxic metal decontamination of aqueous solutions. J. Mol. Liq. 2019, 295, 111684. [CrossRef] 